\title{
Exercise is Medicine: Some Cautionary Remarks in Principle as Well as in Practice
}

Ross Neville

Technological University Dublin, ross.neville2@student.dit.ie

Follow this and additional works at: https://arrow.tudublin.ie/tfschhmtart

Part of the Sports Sciences Commons

\section{Recommended Citation}

Neville, R.D. (2012) Exercise is medicine: Some cautionary remarks in principle as well as in practice, Medicine, Health Care and Philosophy. doi:10.1007/s11019-012-9383-y

This Article is brought to you for free and open access by the School of Tourism \& Hospitality Management at ARROW@TU Dublin. It has been accepted for inclusion in Articles by an authorized administrator of ARROW@TU Dublin. For more information, please contact arrow.admin@tudublin.ie, aisling.coyne@tudublin.ie, gerard.connolly@tudublin.ie.

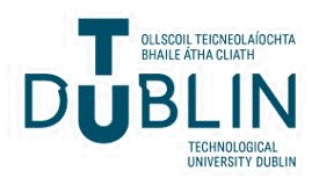




\title{
Exercise is medicine: Some cautionary remarks in principle as well as in practice
}

\author{
Ross D. Neville \\ Dublin Institute of Technology
}

\begin{abstract}
On the basis of extensive research on the relationship between physical activity, exercise and health, as well as strong support from policymakers and practitioners, the "Exercise is Medicine" initiative has become something of a linchpin in the agenda for modern healthcare reform and reflects a broader acceptance that the philosophy of health politics must shift from social engineering to performativity. However, in spite of the avowed commitment to encouraging individuals to take on a more reflexive relation to their health, it remains unclear as to whether an initiative such as this is, unambiguously, a good thing. In this paper, a number of cautionary remarks are made with respect to "Exercise is Medicine" in principle as well as in practice. Firstly, it is argued that equating exercise with medicine is to equate it with a definition of and relation to the body to which it is not entirely akin. And secondly, it is argued that any proposed alignment of the fitness and healthcare industries needs further critical examination, a realigning of interests, and a thorough reconsideration of their suitability of fit.
\end{abstract}

Keywords "Exercise is medicine" · health and fitness - object- vs. subject-centred risk · fitness and healthcare industries 


\section{Introduction}

If, as Foucault $(1980,1995,1998)$ explained, each historical epoch has specific ways of producing the kinds of bodies that align with its needs as an economic system, then the burgeoning "Exercise is Medicine" initiative is a prime example of how individuals are now encouraged to act as autonomous and responsibly-informed, make cost-benefit analyses of life-options, and take on a more reflexive relation to their health. On the basis of extensive research on the relationship between physical activity and health, as well as strong support from policymakers and practitioners, this initiative has become not only a linchpin in the agenda for modern healthcare reform but a reflection of the broader acceptance that the philosophy of health politics must shift from social engineering to performativity. That "Exercise is Medicine" is now something of a platitude is a testament, not only to the cogency of this claim, but to its growing advocacy and the fact that it has become conceptually embedded within our system of formal and informal inferences with respect to health.

In spite of the avowed commitment to encouraging a change in the behavioural and lifestyle trajectories of modern individuals, however, it remains unclear as to whether an initiative such as this is, unambiguously, a good thing. This is not only because the remit of concern to which it extends is broader than the medical and scientific relations of its production, but because the possibility of its critical examination is almost entirely negated for the most important of those involved in its uptake and implementation - its participants.

The purpose of this paper is to draw on a number of important sociological and philosophical insights in order to make cautionary remarks with respect to "Exercise is Medicine". It will do so in two ways. The first section highlights a number of important distinctions that problematise the equating of exercise and medicine in principle. It will be argued that "exercise" and "medicine" appeal to quite different concerns with, and relations to, the body and that equating exercise with medicine is to equate it to a definition of the 
body and standards of reference to which it is not entirely akin. On the basis of this logical distinction, the second aspect of this paper reconsiders the assertions made by Sallis' (2009) that (i) the fitness and healthcare worlds seldom interact, and that (ii) on the basis of the "Exercise is Medicine" initiative, there should be a merging of the fitness industry with the healthcare industry. It will be argued firstly that (i) is not entirely true and, secondly, that, although the imperative of (ii) has clear merits that will be highlighted, it needs further critical examination and must be approached with caution. The paper concludes by highlighting some avenues for future research and debate and considerations for practice.

\section{Considering exercise and medicine as relations to the body}

Although the launch of the initiative proper was precipitated by a number of related previous studies of the same name (Bryant and Peterson 2006; Burnham 1998; Elrick 1996), "Exercise is Medicine" is now largely synonymous with the collaborative project initiated by the American Medical Association (AMA) and the American College of Sports Medicine (ACSM) in 2007 in order to encourage a change in healthcare provision towards the prevention of disease through exercise (Jonas and Phillips 2009; see also Pearce 2008; Sallis 2009). The initiative came to the fore on the back of the widely held assumption that mainstream medical practice had largely ignored the value of exercise and that there was significant potential for making its assessment and prescription a standard part of the modern treatment paradigm. ${ }^{1}$ On this basis, it calls for physicians and other related clinical healthcare professionals to commit to the advocacy and advancement of the principles of exercise, to use patient activity levels as a vital sign in helping to lower the risk of all-cause mortality (principally cardiovascular disease, hypertension, diabetes, and obesity), and to do so in a structured and controlled manner. "Exercise is Medicine" is now something of a global phenomenon. In 2010, for example, the initiative held its first World Congress and hosted delegates from 60 countries outside of the U.S. (its country of origin). In addition to this, and at the Second Annual World Congress in 2011, the "Exercise is Medicine Global 
Health Care Declaration" was introduced in order to further position the initiative at the forefront of the disease treatment and prevention paradigm on the back of the following claim: Exercise on prescription is the world's prescription for health.

In order to explore the implications of this initiative and the slogan "Exercise is Medicine" more specifically, it will be useful to consider the relation to the body that each of these terms have generally presupposed. Basic word association will reveal that "Exercise is to Medicine" as "Fitness is to Health" and, taken in this manner, it can be seen that "Exercise is Medicine" is a logical and practical extension of the assumption that fitness leads to health. To put it another way, "Exercise is Medicine" is a logical and practical extension of the assumption that "being fit" invariably implies "being healthy". This is a position that is well rehearsed in the sports/exercise science literature and might usefully be referred to as the hierarchical model. It implies treating "fitness" and "health" in a discrete manner, as belonging to the same order of causality, and that fitness is oriented towards health as its higher-order construct. This hierarchical relation between fitness and health is scarcely contested and can be phrased thusly: physical activity and exercise contribute to fitness which contributes to positive health outcomes (or overall wellbeing). ${ }^{2}$

From the perspective of the sociology of body/sociology of health and illness in particular, this is a problematic connection. This is not merely for the well known fact that not all fitness activities are good for one's health, but also because aligning fitness and health is deeply political (see e.g. Glassner 1989, 1990; Markula 1997, 1998; Pronger 2002; Smith Maguire 2008a; White et al. 1995). Although the sections that follow will discuss the political implications of this connection in more detail, it will be helpful for the purposes of the present section to focus on the observation that, although they are often used synonymously (or have come to be used almost synonymously), "fitness" and "health" (and thus exercise and medicine) appeal to quite different concerns with, and relations to the body (Bauman 1998, 
2000, 2001, 2005; Bauman and May 2001; Glassner 1989, 1990). The following sections illustrate a number of conditions under which this appears to be the case.

Health and fitness: From object-centred to subject-centred risk

A useful context for framing the shift in emphasis from health to fitness (and hence from medicine to exercise) is the one that has occurred from dangerousness to risk. While various theorists have discussed the centrality of the concept of risk to the configuration of modern societies (Beck 1992; Giddens 1990, 1991), it is Castels (1991) who has argued quite specifically that risk has become autonomous from danger. "A risk", Castels (ibid, p. 287) explains, "does not arise from the presence of a particular precise danger embodied in a concrete individual or group". Rather, with risk "[i]t is the effect of a combination of abstract factors which render more or less probable the occurrence of undesirable modes of behaviour [or outcomes]". For Castels, the shift from dangerousness to risk is based on the Foucauldian premise that power is "not to be sought in the...existence of a central point", but in the "complex strategical situation in a particular society" (Foucault 1998, p. 93). For Castels then, risk is incompatible with the type of substantialism presupposed by danger. That is to say, unlike danger which is localised, risk is thoroughly relational.

Despite the sociological context of its development, this is more than an abstract observation. For example, modernisation, which has brought with it significant advances in biomedical science and technology, has facilitated a shift away from the dangers of, say, acute and infectious diseases to a heightened awareness of, and anxiety with respect to, the risks of noncommunicable conditions that are chronic and degenerative in character. Modern epidemics quite clearly reflect this shift. According to Boero (2010), modern epidemics problematise the traditional paradigm of cause and effect given their lack of a clear pathological base. The moral panic that accompanies Type 2 diabetes, heart disease, and obesity, for example, is explained by the fact that modern bodies are always potentially at risk; not necessarily to some pathogen external to them, but to their very composition. Risk 
produces its effects from the inside out and not merely the other way round as was traditionally the case. That is to say, risk is subject-centred as opposed to dangerousness which is object-centred. It is everywhere in modern society, not because it embraces everything, but because it potentially comes from everywhere.

This shift has, in a very significant way, prefigured the shift in emphasis from health to fitness (and hence from medicine to exercise). As Petersen (1997 p. 195) explains, "the distinction between healthy and unhealthy populations [has] totally dissolve[d] since everything potentially is a source of 'risk' and everyone can be seen to be 'at risk'”. Just as dangerousness and risk appeal to quite different concerns with the body, so too do health and fitness. Health corresponds to dangerousness (or object-centred risk) in that it is concerned with the body at stasis. Threats to the normal functioning of the healthy body are treated as alien presences to its mechanistic structure which exert upon individuals a telic demand, to use Leder's (1990) phrasing. These object-centred risks, once imposed on the healthy body, are to be meliorated reactively, and in a deductive manner. In the following passage, Baron (1992; see also Leder 1992) offers a useful explanation of how these objectcentred risks are treated at the level of practice:

[P]hysicians are trained to regard the body as an impediment to diagnosis...[T]he living body of the patient presents an obstruction that hides a deeper truth. It is a translucent screen on which the silhouette of disease is projected; the physician's task is to render the patient's body (and the patient) transparent so that true disease can be directly apprehended...The body as a physical object like all other physical objects becomes a literal metaphor for clinicians...Disease becomes an act of struggle with the body, the art of comprehending bodily characteristics so that they can be subtracted from the "clinical presentation" leaving one the clearest view of the disease (Baron 1992, p. 38). 
This is not necessarily the case with fitness. Fitness presupposes anything but the body at stasis. Rather, with fitness, one's body is to be lived through, not merely lived with. In fact, with fitness, it is not so much the case that I have a body. Rather, as Marcel (1977, p. 100) so eloquently put it, "my body it mine in so far as for me my body is not an object but, rather, I am my body". Fitness presupposes what Merleau-Ponty (2002; see also Edwards 1998; Leder 1990, 1998) referred to as the living body, one that is wholly animated and presupposes itself as a body-subject. To be fit or to engage in fitness activities is to be in the business of disease prevention. It is to be in the business of risk management and reduction, an inductive process that is undertaken in and through the body with a view to preserving or restoring its vitality. As such, with fitness the telic demand to which Leder refers is ceaselessly imposed upon the body since there only exists the threat of an alien presence; or rather, since there always exists the threat of an alien presence. Fitness, as a desirable bodily state then, provides the first line of defence in the face of subject-centred risks that are to be obviated in a proactive manner. As Bauman (1998, p. 23) explained, being fit implies "being always on the move". It means having a "flexible, absorptive and adjustable body, ready to live through sensations [that are] impossible to specify in advance" (Bauman 2000, p. 77). It implies "being ready for all challenges, and [being] indifferent to the nature of any task it may confront" (Bauman 1992, p. 31). In fact, even in the absence of any concrete external threat imposed upon the body, fitness takes on the character of covering all of one's bases in the face of unremitting ambivalence and ontological insecurity. That is to say, far from being merely concerned with health and being subject to risks acting on the body, with fitness, modern individuals have become engaged as subjects of risk both in and through their bodies.

Exercise was medicine: From what is a body? to what can a body do?

Whereas health follows a typically substantive logic insofar as its locus of knowledge is abstracted from context and foregrounded in the material configuration of individual bodies, 
fitness implies being fit for something or, perhaps more insidiously, fit for someone. Unlike health, fitness orients individuals primarily towards the future in an instrumental sense. With fitness, one no longer merely speaks of the baseline requirements of the body but of its potential - to affect and to be affected. And on this basis, in advanced modern societies there is an overwhelming shift away from concerns about health and effects imposing upon the normal functioning of the body to concerns with the body's fitness and the constitution of new sets of affective relations. That is, it is not only the case that advanced modern societies engage their members in an active rather than a passive manner. Rather, they also require a shift in emphasis from body-object to body-subject, from having a body to being one's body, and from the passive consumption of expert medical discourses to the active production of their embodied and creative destinies. That is to say, in a manner akin to that outlined in Spinoza's Ethics, they require a shift in emphasis in life orientation from the question What is a body? to the question What can a body do? (Buchanan 1997; Deleuze and Guattari 1987; Fox 2002). The bases for the attribution of a logical distinction between health and fitness are highlighted in the following table:

Table 1. On the logical distinctions between health and fitness

\begin{tabular}{|l|c|c|}
\hline & "Health" & "Fitness" \\
\hline Type of risk engendered & Object-centred & Subject-centred \\
\hline Orientation to the body & Epistemological & Ontological \\
\hline Concern with the body & $\begin{array}{c}\text { Baseline requirements } \\
\text { (What is a body?) } \\
\text { (Effects) }\end{array}$ & $\begin{array}{c}\text { Potential } \\
\text { (What can a body } \\
\text { do?) } \\
\text { (Affects) }\end{array}$ \\
\hline Type of body presupposed & Body-object & Body-subject \\
\hline Relation to the body & Having a body & Being one's body \\
\hline Role to be undertaken & Passive consumer & Active producer \\
\hline
\end{tabular}




\section{Aims of health context}

Social engineering

Performativity

Whereas the "Exercise is Medicine" initiative is certainly reflective of this shift in the health context from social engineering towards performativity, it is unclear as to whether or not it goes far enough. That is to say at the very least, on this account of the dual character of the body and the types of risk it now presupposes, it seems as though there may be broader issues of commensurability that have been largely ignored (see McNamee 2005). The table outlined above certainly provides a useful frame within which this question of commensurability might be considered in the future. However, taken to its extreme, and for the purposes of argument here, it might even seem instructive on the basis of these distinctions to regard health as having fallen into a class that prominent sociologist Ulrich Beck has referred to as "zombie categories" (Beck and Beck-Gernsheim 2002; Beck and Willms 2004).

[T] he sociological imagination is now inhabited by zombie categories. They haunt our thinking. They focus our attention on realities that are steadily disappearing. And they haunt our empirical work, because even the subtlest empirical work, when framed in zombie categories, becomes blind empiricism. Zombie categories embody nineteenth-century horizons of experience...And because these inappropriate horizons...still mould our perceptions, they are blinding us to...real experience[s] and the[ir] ambiguities (Beck and Willms 2004, p. 19).

Is health a zombie category? Has it lost its conceptual and explanatory powers? Well, much debate would be needed in order to gain consensus on such a claim. What is clear, however, is the fact that modern conceptions of the body in general and modern epidemics in particular exist in an awkward relation to health. In fact, that modern epidemics are framed as the major health problems of our time is something of a logical misnomer. Is it not the case that modern epidemics problematise health? Is it not something of a category mistake to say that "Exercise is Medicine"? Might it be the case in the future that we stop talking 
about how "Exercise is Medicine", reflect back on the shift that occurred "From Medicine to Exercise", and perhaps even talk about the fact that, for a great period in our intellectual history, "Exercise was Medicine"? Probably not. But the possibility that traditional conceptions of health, and thus medical practice, are focusing our attention on realities that are steadily disappearing is thought-provoking nonetheless.

\section{Health and fitness: A confluence of interests?}

On the basis of the foregoing, there are two quite specific statements in Sallis' (2009) paper, "Exercise is medicine and physicians need to prescribe it!", that should be less self-evident than they appear to be. Taking them in the reverse order that they are outlined in the paper, Sallis (ibid, p. 4) asks "Why does th[e] fitness world seldom intersect with the healthcare world?" and, on this basis, states that "It is clear to me that we must begin to merge the fitness industry with the healthcare industry if we are going to improve world health" (ibid). The following two sections are given to the analysis of this question and follow-up statement, respectively, and mark a number of useful clarifications, considerations, and issues for practice.

The healthcare and fitness worlds: A case of "never the twain shall meet"?

The premise that the fitness and healthcare worlds do not intersect is, in a certain sense, clearly untrue. According to Smith Maguire (2008a, b), the legitimacy of the fitness industry is largely parasitic upon endorsements from the health field. In fact, the fitness industry is perhaps unparalleled in terms of the level of endorsements that it receives from fields external to, and independent of it. In a more fundamental sense, however, it can also be seen that the fitness field quite clearly hangs on to the "epistemological coat-tails" (Morall 2009 , p. 96) of the broader field of health medical discourse. That is to say, that fitness and health speak to quite different relations to the body is scarcely acknowledged in the sports/exercise science literature. That fitness also routinely functions as a universal, and 
thus objective, resource of judging the adequacy of modern bodies is a testament to the proximity between these two fields of practice. The organisation of the fitness field as an official scientific discourse has, in fact, relied heavily on the development of systems of classification and diagnostic procedures that it has adapted from the health field. It too combines examination and observation in order to codify its subject and, in conjunction with its confessional practices, procedural examinations and interventions, seeks to reduce the frequency with which deviation from the norm occurs. This is a model that is clearly inherited from the broader field of health. And one might go even further than Smith Maguire and say that the fitness field is not merely legitimised by the health field but is dependent on it for many of its terms and frames of reference.

The notion that the fitness and healthcare worlds seldom intersect cannot be totally true because they are bound together in a labyrinth of formal and informal relations. A more fitting question to ask on the basis of the foregoing is to what extent the fitness field is guilty of a methodological atavism on the back of its alignment to standards of reference to which it is not entirely akin. As was highlighted in the previous section, is there not a commensurability issue at stake between the body (-object) of health and the body (-subject) that fitness presupposes? It is questions such as these that appear particularly timely and worthy of being addressed for future clarification. It is insufficient to treat the problem of the relation of fitness and health as merely empirical, which is commonplace. To continue to do this is to proceed in a largely unreflexive manner and, as a consequence, without due consideration for the narrative field as a whole.

In a broader sense, Sallis is quite right to observe that the fitness and healthcare worlds seldom intersect. That is, it is quite right to observe that there is something of a functional separation at play. This functional separation, however, is more than naively or uncritically maintained and it would be remiss to overlook the political agenda that might be at stake here. The risk context is worth underscoring again here. The opening up of a market 
for fitness products and services, and its relative autonomy from the health field, represents a shift away from what Giddens and Pierson (1998, p. 163) referred to as "external risk" the presumption that the state will intervene and protect its citizens when things go wrong to a more active "reflexive risk environment" under which people are encouraged to establish a different relationship to their social an economic conditions. The relative autonomy of these fields is fuelled by a decades-old agenda to shed an economic burden (one that is compounded by changing demographics and increasing demands) and is essential to the maintenance of an environment under which individuals are encouraged to act as autonomous, responsibly-informed individuals who make cost-benefit assessments of life options. In fact, as Beck and Beck-Gernsheim (2002) have explained, this individualising trend is not a social condition arrived at by the decisions of willing individuals. Rather, in our modern social configuration, "people are condemned to individualization" (ibid, p. 4). That the fitness and healthcare worlds do not fully intersect enables the latter to absolve from a traditional interventionist role by encouraging an increasingly privatised attitude towards risk and an inversion in the burden of responsibility onto individuals and individual behaviours. Taking Sallis' (2009, p. 3) assertion that '[t]he three major factors that influence our health and longevity are genetics, the environment and behaviour" then, it is clear that it is the latter that has been deemed the most economically prudent area for the development of health policy.

\section{"Exercise is medicine": Consumption myopia, leisure, and the obligation of self work}

On the basis of the foregoing, it should be clear that Sallis' recommendation that there should be a merging of the fitness and healthcare industry is less self-evident than initially supposed. For one, what is meant by this merger, and what it would involve specifically? The benefits of such a merger to the healthcare industry seem to be already well articulated. However, whether they extend a great deal beyond mere economic factors is much less clear. At the policy level, for example, the emphasis on individual behaviours, personal 
choice, and increased levels of consumption as opposed to an emphasis on environmental and infrastructural factors does little to alleviate this scepticism. That is to say, the bases for emphasising the former appear little more than economically driven, especially since the latter could be deemed much less attractive in that they would likely require a heavy strategic investment in resources and development initiatives at the level of the material environment.

Given the magnitude of the scale of difference between the private and public provision of fitness services, the benefits to the fitness industry over and above economic factors are even less clear. For example, a merger would seem to align more closely with the interests of the public provision of services than it would with the private sector and it is unclear as to how this distinction could be negotiated. That is to say, while a merger between the public provision of fitness and healthcare services could potentially result in the establishment of a broader range of shared, social and community-based performance indicators as standards of reference and success (and this, of course, would be something to aspire to), it is unclear as to whether their private corollaries are wont to take leave of their emphasis on the logic of consumption, not least their economic myopia. To be sure, there has been an increasing emphasis on innovation between both industries through calls for collaborative research and practice (e.g. the €4.2m made available from the ESRC in July 2011 to work towards increasing healthy life expectancy in the EU by 2020), the development and rolling out of activity initiatives and referral schemes (general initiatives as well as more focused referral schemes such "Exercise is Medicine", or the GP Exercise Referral Scheme as they are also known as), as well as a significant improvement in terms of the standards of regulation and practice with respect to the level of professionalism within the fitness industry (such as the agreed upon code of ethical practice that forms the basis for the Register of Exercise Professionals, or "REPS"). However, it is unclear as to whether any of these will contribute significantly towards making access to fitness and healthcare services less differentially available. And this, it seems, should form the very foundation of 
such a collaborative programme. What seems more likely is that a broad scale merger would continue to involve serious compromises to get both sides on board and, thus, proceed at the expense of the social context that inspired it in the first place.

The final consideration pertains more specifically to the role and effect of an initiative such as "Exercise is Medicine" under such a merger. The public hopes for such a project will not only be met with the reality that the modern fitness context is heavily privatised through fee-based membership, but is also privatised in the sense that its activities are undertaken in the context of leisure time (Sassatelli 1999a; Smith Maguire 2008a). "Exercise is Medicine", however, appears to impose an instrumental rationality upon exercising and it is unclear as to whether it would do so at the expense of those expressive characteristics often associated with leisure. That is to say, "Exercise is Medicine", as it is presently conceived, seems to construct a sphere in which the freedom to engage in expressive activities is replaced by what Smith Maguire (2008b, p. 59) referred to as the "obligation of self work". This naturalisation of exercising and self-work as leisure is problematic for some (Rojek 2010; Smith Maguire 2008a, b). For example, one might ask quite specifically to what extent "Exercise is Medicine" is an imposition on peoples' leisure time? At an even broader level, one might ask to what extent the cultural imagery of leisure, recast through the lens of such initiatives, would require a shift in emphasis and the inculcation of values traditionally associated with work. Would this make exercising less likely to be framed as a leisure experience? These are question that deserve further examination because, although "Exercise is Medicine" exists in an uneasy relation to leisure, those practices prescribed seem to have been naturalised as leisure activities (Smith Maguire 2008a, b). ${ }^{3}$

Due consideration to how the "Exercise is Medicine" initiative is promoted in the future and the types of values that it is thought to engender should be of primary concern. This is especially important insofar as there is a danger that, by instrumentalizing leisure time through the obligation of self-work, exercising might be rendered meaningless except 
as a means of acquiring values that are external to it (Maclntyre 2007; McNamee 1994). It would be particularly useful to address how the expressivity of exercise as it is undertaken in leisure time might be reconciled with the instrumental character of the "Exercise is Medicine" initiative. The extent to which such programmes can orient individuals towards the types of expressive features that are internal to the practice of exercise, it seems, will not only be critical factors to the initiative's success but to its longevity as well.

\section{Conclusion}

I hope it is clear at this point that the intention in problematising "Exercise is Medicine" was not at all polemical. Rather, in questioning this connection, I hope to have shown that the types of bodies to which each of these terms refer are quite apart from each other in terms of their relation to the individual and to society, and to risk in particular. On this basis I hope to have shown that, with the term "Exercise is Medicine", there is actually a tension where what is being sought is a confluence. As a philosophy for tackling the problems of modern health, it seems as though the future of the "Exercise is Medicine" initiative is not only reliant on a seemingly simple realigning of interests between the fitness and healthcare industries, but on a thorough philosophical reconsideration in the future of the terms themselves and their suitability of fit.

Looking beyond this paper, it is clear that future consideration is needed in order to highlight and clarify the asymmetries that are at play in an initiative such as "Exercise is Medicine". And, perhaps the most important question to be asked of it going forward is to what extent the objectives of such a programme are produced in the service of broader political and economic interests? While "Exercise is Medicine" is indeed framed as a voluntarist project, the imposition of socially borne risk onto individual leisure time is not a social condition that is arrived at by individuals in a voluntarist manner. It is, quite frankly, an imposition of what Bourdieu and Passeron (1977, p. 4) have referred to as "symbolic violence". An initiative such as "Exercise is Medicine" needs to do more than direct socially 
borne risk onto individuals and direct them towards the market for its relief. That is, they need to do more than make the problems of health problems about mere increases in consumption activity. This is not only an imperative because of the social implications that underpin such an initiative, but because there is a potential for it to attract much attention on the basis of lucrative economic exchanges that it could likely engender. In order that this might be avoided, the future of "Exercise is Medicine" would likely benefit from exploring further the possibilities for defining its mission on more egalitarian and developmental terms. It would benefit from a shift in emphasis from mere consumption activity to experience. That is, from a shift in emphasis from the narrow goal of improving fitness through individual activity to the broader goal of improving the relations of fit individuals experience between themselves and their social-material environments.

\section{Notes}

1. For a general overview, see www.exerciseismedicine.org. It is also worth noting that, outside of the U.S., comparable initiatives have been referred to as GP referral schemes. For example, in Ireland, the "GP Exercise Referral Programme" is the name for the joint scheme that is being undertaken in conjunction with the Institute of Leisure and Amenity Management (ILAM), the Health Service Executive (HSE), and the Irish College of General Practitioners (ICGP).

2. Although the relation of fitness and health to wellbeing is not of primary concern here, it seems as though this also represents a useful conceptual problem for future consideration.

3. A number of recent studies, for example, suggest that emphasising the instrumental and beneficial outcomes of exercising can act, somehow paradoxically, as a barrier to the uptake and maintenance of such behaviour (see e.g. Crossley 2006; Sassatelli 1999b; Tsai 2005). 


\section{References}

Baron, RJ. 1992. Why aren't more doctors phenomenologists? In The Body in Medical Thought and Practice, ed. D. Leder, 37-50. Dordrecht, NED: Kluwer Publications.

Bauman, Z, and May, T. 2001. Thinking sociologically (2 ${ }^{\text {nd }}$ Ed.). Malden, MA: Blackwell.

Bauman, Z. 1992. Morality, immortality, and other life strategies. Stanford, CA: Stanford University Press.

Bauman, Z. 1998. On postmodern uses of sex. Theory, Culture \& Society 15 (3): 19-33.

Bauman, Z. 2000. Liquid modernity. Cambridge: Polity Press.

Bauman, Z. 2001. The individualized society. Cambridge: Polity Press.

Bauman, Z. 2005. Liquid life. Cambridge: Polity Press.

Beck, U. 1992. The risk society: Towards a new modernity. London: Sage.

Beck, U., and Beck-Gernsheim, E. 2002. Individualization. London: Sage.

Beck, U., and Willms, J. 2004. Conversations with Ulrich Beck. Cambridge: Polity Press.

Boero, N. 2010. Bypassing blame: Bariatric surgery and the case of biomedical failure. In Biomedicalization: Technoscience, Health, and IIIness in the U.S., ed. A.E. Clarke, Mamo, L., and Fosket, J.R., et al., 307-330. Durham, NC: Duke University Press.

Bourdieu, P., and Passeron, J.C. 1977. Reproduction in education, society and culture. London: Sage.

Bryant, CX., and Peterson, JA. 2006. Exercise is medicine. In Complementary Medicine in Clinical Practice, eds. DP Rakel, and Faass, N., 125-130. London: Jones and Bartlett. 
Buchanan, I. 1997. The problem of the body in Deleuze and Guattari, or, what can a body do? Body \& Society 3 (3): 73-91.

Burnham, JM. 1998. Exercise is medicine: Health benefits of regular physical activity. $J$ La State Med Soc 150 (7): 319-323.

Castels, R. 1991. From dangerousness to risk. In The Foucault Effect: Studies in Governmentality, ed. G. Burchell, Gordon, C., and Miller, P., 291-298. London, UK: Havester Wheatsheaf.

Crossley, N. 2006. In the gym: Motives, meaning and moral careers. Body \& Society 12 (3): 23-50.

Deleuze, G., and Guattari, F. 1987. A thousand plateaus: Capitalism and schizophrenia. Minneapolis: University of Minnesota Press.

Edwards, SD. 1998. The body as object versus the body as subject: The case of disability. Medicine Health Care and Philosophy 1 (1): 47-56.

Elrick, H. 1996. Exercise is medicine. Phys Sportsmed 24 (2): 72-76.

Foucault, M. 1980. The politics of health in the eighteenth century. In Power/Knowledge: Selected Interviews and Other Writings, 1972-1977, ed. C. Gordon, 166-182. New York: Pantheon Books.

Foucault, M. 1995. Discipline and punish: The birth of the prison. New York: Vintage Books.

Foucault, M. 1998. The will to knowledge: The history of sexuality 1. London: Penguin.

Fox, NJ. 2002. Refracting health: Deleuze, Guattari and body/self. Health 6 (3): 347-364.

Giddens, A. 1990. The consequences of modernity. Stanford, CA: Stanford University Press. 
Giddens, A. 1991. Modernity and self-identity: Self and society in the late modern age. Cambridge: Polity Press.

Giddens, A., and Pierson, C. 1998. Conversations with Anthony Giddens: Making sense of modernity. Stanford, CA: Stanford University Press.

Glassner, B. 1989. Fitness and the postmodern self, Journal of Health and Social Behavior 30 (2): 180-191.

Glassner, B. 1990. Fit for postmodern selfhood. In Symbolic Interaction and Cultural Studies, ed. H.S. Becker and McCall, M.M., 215-243 .Chicago, IL: University of Chicago Press.

Jonas, S., and Phillips, E.M. 2009. ACSM's exercise is medicine: A clinician's guide to exercise prescriptions. Philadelphia, PA: Lippinicott Williams \& Wilkins.

Leder, D. 1990. The absent body. Chicago, IL: University of Chicago Press.

Leder, D. 1992. A tale of two bodies: The Cartesian corpse and the lived body. In The Body in Medical Thought and Practice, ed. D. Leder, 17-36. Dordrecht, NED: Kluwer Publications.

Maclntyre, A. (2007) After virtue: A study in moral theory ( $3^{\text {rd }}$ Ed.). London: Duckworth.

Marcel, G. 1997. The mystery of being. South Bend, IN: Gateway.

Markula, P. 1997. Are fit people healthy? Health, exercise, active living, and the body in fitness discourse. Waikato Journal of Education 3 (1): 21-40.

Markula, P. 1998. Women's health, physical fitness and ideal body: A problematic relationship. Journal of Physical Education New Zealand 31 (1): 9-13.

McNamee, M. 2005. Positivism, popper and paradigms. In Philosophy and the Sciences of Exercise, Health and Sport: Critical Perspectives on Research Methods, ed. M. McNamee, 1-20. Abingdon, UK: Routledge. 
McNamee, MJ. 1994. Valuing leisure practices: Towards a theoretical framework. Leisure Studies 13 (4): 288-309.

Merleau-Ponty, M. 2002. Phenomenology of perception. London: Routledge.

Morall, P. 2009. Sociology and health: An introduction. New York: Routledge.

Pearce, PZ. 2008. Exercise is medicine. Current Sports Medicine Reports 7 (3): 171-175.

Petersen, A. 1997. Risk, governance and the new public health. In Foucault, Health, and Medicine, ed. A. Petersen, and Bunton, R., 198-206. London: Routledge.

Pronger, B. 2002. Body fascism: salvation in the technology of physical fitness. Toronto, ON: University of Toronto Press.

Rojek, C. 2010. The labour of leisure: The culture of free time. London: Sage.

Sallis, RE. 2009. Exercise is medicine and physicians need to prescribe it! British Journal of Sports Medicine 43 (3-4): 3-4.

Sassatelli, R. 1999a. Interaction order and beyond: A field analysis of body culture within fitness gyms. Body \& Society 5 (2-3): 227-248.

Sassatelli, R. 1999b. Fitness gyms and the local organization of experience. Sociological Research Online 4 (3). http://www.socresonline.org.uk/4/3/sassatelli/html.

Smith Maguire, J. 2008a. Fit for consumption: Sociology and the business of fitness. London: Routledge.

Smith Maguire, J. 2008b. Leisure and the obligation of self-work: An examination of the fitness field. Leisure Studies 27 (1): 59-75. 
Tsai, EHL. 2005. A cross-cultural study of the influence of perceived positive outcomes on participation in regular active recreation: Hong Kong and Australian university students. Leisure Sciences 27 (5): 385-404.

White, P, Young, K, Gillett J. 1995. Bodywork as a moral imperative: Some critical notes on health and fitness. Society and Leisure 18 (1): 159-182. 